\title{
Project-Based Learning Module Development of Wearable Computing for the Internet of Things (IoT)
}

\author{
(Innovations in engineering and education)
}

\author{
Ghina Nadifah Amani*, Yoyo Somantri, Didin Wahyudin \\ Department of Electrical Engineering Education \\ Universitas Pendidikan Indonesia \\ Bandung, Indonesia \\ *ghinanadifah@student.upi.edu,ysomantri@upi.edu,deewahyu@upi.edu
}

\begin{abstract}
This research explained about the learning module development of Wearable Computing for IOT which was conducted in XI class of Engineering Electronics Industry at SMK Negeri 1 Cimahi which is one of the Vocational Secondary education Institutions in Cimahi City, West Java, Indonesia. This research focused on several aspects such as the project-based learning module development with ADDIE model, teachers' and students' feedback towards this module. This research involved teachers, four students to get involved in limited test, and 32 students who expressed their feedback regarding the module. The data analysis of students' response questionnaire was done with the Mann Whitney's U Test and Kruskal-Wallis to compare students' responses which were divided into several categories. This research produced the learning module of Wearable Computing for IoT, the contents of this module has been quite detailed and reliable based on teachers' point of view, and $94 \%$ $(n=32)$ of students believed that the module is able to be used in the classroom, and limited test resulted the experiment that suitable with the module objectives. Thus, to maximize the use of learning module of Wearable Computing for IOT in the classroom, students might need to improve creativity in terms of the development of each experiment and teachers can use the module as a source of learning with managing to do a development.
\end{abstract}

Keywords-learning module, wearable computing, IoT, Project Based Learning (PjBL), Mann Whitney's U Test, industrial electronics engineering

\section{INTRODUCTION}

Wearable Computing is one of the new studies of science in the field of technology which involves the interaction between humans and computers to produce devices that can be used by human, wearable computing is more familiar with the term wearable device [1]. Meanwhile $\mathrm{Xu}$ [2], wearable device is a type of portable equipment, which is based on human capacity and equipment function. Wearable device referred to as a merger of several technologies, such as electronics technology (sensors), computing (computers and microcontrollers), and communications which become the important parts of technology nowadays [3]. Some research related to Wearable Computing such as Shanmugam AL [4] uses several constituent components of Wearable Computing which are easily obtained, developed, and required low cost of manufacture. Study Sani et al. [5] makes a wearable tool which functions to carry out the monitoring on Heart Rate.

The sources of teaching materials using modules are able to respond the curriculum needs that prioritize students-centered learning. The module is a teaching material that systematically compiled with a language that is easily understood by students in accordance with the level of knowledge and age, in order to learn individually with the minimal guidance of educators. With the module, students are able to measure their own mastery level of learning material for each individual [6]. The arrangement of learning modules that will help students in understanding Wearable Computing was compiled by one of the learning models. One of the innovative learning models that can lead students is project-based learning (PBL) [7]. The selection of project-based learning module provides the chance to improve students' learning habits and to direct students to think originally until at the end, they are able to solve a problem in real life [6].

Material of modules are arranged by noticing to the basics of the introduction of Wearable Computing which are as follow, a constituent component used in the experiments process, connecting with IOT, and the program design of the software along with one of the examples of wearable device to determine air condition and digital clock. Therefore, the module is expected to help students to be able to develop a material that is given in studying the recent technologies development which are closely related to the disciplines of science that students learn in school. The observation results in the field and discussions with teachers -during the implementation of PPLSP which is a program for undergraduate- found out that the learning modules can be developed and tested in XI class of Engineering Electronics Industry at SMK Negeri 1 Cimahi which at that time was studying about Arduino IDE. Arduino IDE is one of the teaching materials contained in the designed learning module. 
Hence, with this module, it is expected that students can learn and develop what they already learned. Further, this module is expected to be applied either in the classroom or outside the class. This present research aims at conducting the development of project-based learning module of Wearable Computing for the Internet of Things (IoT) and at recognizing both teachers' and students' feedback on learning module of Wearable Computing for the Internet of Things (IoT). Formatter will need to create these components, incorporating the applicable criteria that follow.

\section{METHODS}

This research is a development research using the ADDIE Model. ADDIE development model includes several steps as follow: analysis, development, implementation, and evaluation [8]. In this study, the steps of ADDIE development model was only utilized to develop a project-based learning module of Wearable Computing for the Internet of Things (IoT) for XI students of Engineering Electronics Industry at SMK Negeri 1 Cimahi. The implementation and evaluation stage were conducted only to know students' response to this learning module by using some instruments such as a questionnaire, interviews with teachers of Electronic Control Systems subject, and limited experiment. Figure 1 shows the steps in this study.

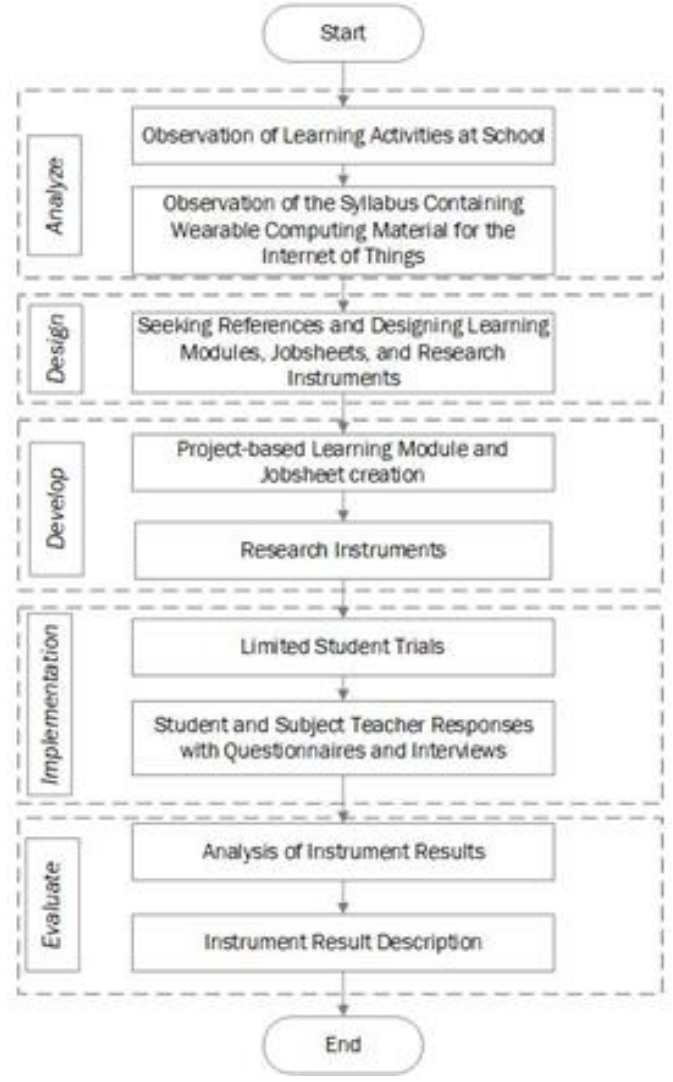

Fig. 1. Diagram flow of research
The techniques of data collection were derived from observations, interviews, and questionnaire. The process of observation lasted during teaching practicum or Program Pengenalan Lapangan Satuan Pendidikan (PPLSP), PPLSP is a specifically program for undergraduate students majoring at education. The observation was done by following and paying attention to the teaching-learning activities and discussion with the teacher. Interview was utilized as a technique of collecting the data in order to know deeper about how teachers' responses towards the learning module and to validate or strengthen the data retrieved by using a questionnaire from students. The questionnaire was distributed in online and included the learning module and video of each worksheet. The respondent of the questionnaire consisted of three classes which were 36 students of XI TEI A Class, 35 students of XI TEI B class, 35 students of XI TEI C class, therefore the number of respondents in this study were 106 people. Sample Purposive was used for this study to obtain the sample, it is also known as judgment sampling, it is a deliberate choice of a researcher using a non-random technique [9]. Data were taken from the $30 \%$ of overall students in total, and the number of respondents was obtained from 10 students per class, this indicated that the number of total respondents was 32 people, who were divided to 18 of male and 14 of female. Four students were involved in the limited test of each experiment that attached on the module.

The data of questionnaire results were analyzed using the Mann-Whitney's U test and Kruskal -Wallis in Statistical Methods for HCI Research by Koji Yatani (yatani.jp) MannWhitney's U-Test [10] which is also known as number test of Wilcoxon Rank, and it is essentially a version of the nonparametric $t$ test. The Mann-Whitney's U Test is used when the dependent variable is ordinal and the dependent variable is a ratio or interval, but it cannot be assumed that the population forms a normal distribution. Therefore, this Mann-Whitney's U Test does not pay attention to the normality of the data. The calculation of the results of this test was done using $\mathrm{R}$ Studio which took into account the results of the $\mathrm{Z}$ value and $\mathrm{p}$-Value. The used code is available on the pages of Statistical Methods for HCI Research by Koji Yatani (yatani.jp) which process the data results of the Scale-Likert. Kruskal-Wallis is basically a non- parametric version of ANOVA. Thus, Kruskal-Wallis is beneficial to be used if there are the data that contain more than two groups to compare, and the data is ordinal or the data cannot assume its normality. Unfortunately, there is no direct way to calculate the Effect Size of the Kruskal Wallis test. As instead, Effect Size can be calculated in a post-hoc test with the Mann-Whitney or Wilcoxon test. Similar to ANOVA, it becomes a need to do a post-hoc test after Kruskal-Wallis if significant effects are found. When we perform multiple $t$ tests with Bonferroni or Holm's correction, we can perform MannWhitney or Wilcoxon tests with the same corrections. First, see how to do a pairwise comparison with the Mann-Whitney test with the Bonferroni correction.

In this study, the Mann-Whitney's U Test was used to compare whether there were differences in the responses of male and female students towards the learning module 
development and Kruskall-Wallis was used to compare the responses among the $\mathrm{A}, \mathrm{B}$, and $\mathrm{C}$ class.

\section{RESULT AND DISCUSSION}

\section{A. Learning Module Development of a Wearable Computing} for Internet of Things (IoT)

1) Analysis stage: At this stage, the researcher conducted an analysis related to the needs of the learning module in the classroom. Observation results revealed the fact that during the process of PPLSP, students were continuing the material which is associated with the Arduino, the material regarding duino becomes the part of material that is designed into the learning module. After discussion had conducted, teacher requested to teach about ESP lesson after Arduino lesson had completely taught. The module was supposed to be used on April, but due to the pandemic, this module only reached the development stage that later will be rated by the students. From the results of analyzing the syllabus, it was obtained the material which was associated with modules such as material that was taken from the Basic Competency of 3.23 "Understanding the control numeric" and of 4.23 "Explaining the work principle of numerically control.

2) Design stage: In this stage, the researcher created the design of the material distribution which contained in the learning module. The results of the design can be seen on the Figure 2. Jobsheet consists of jobsheet 1 Connect to $\mathrm{WiFi}$, jobsheet 2 BME280 sensor, jobsheet 3 Oled Display, and jobsheet 4 challenge.

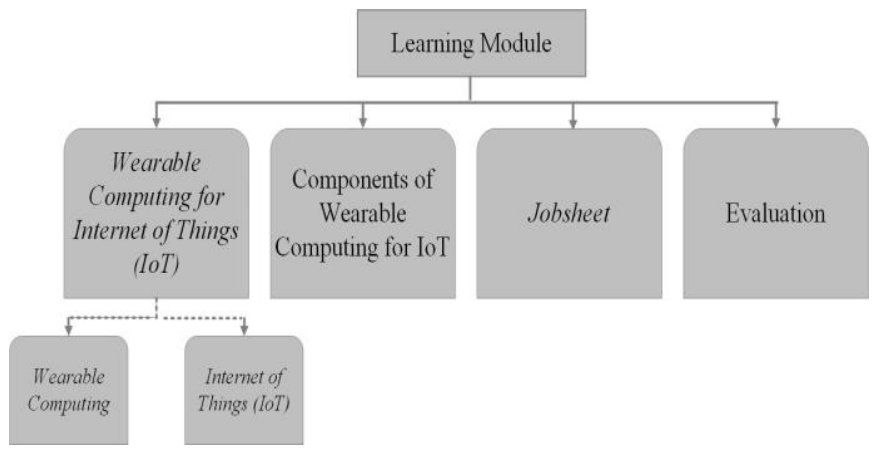

Fig. 2. Results of learning module design,

3) Development stage: This stage generates the learning modules along with the jobsheet, research instruments, assessment of users' response, and limited test. The results of learning module and jobsheet preparation on the material from the learning module can be seen on Figure 3. The material consists of Wearable Computing, FlexIoT IoT Platform, microcontroller, display, and sensors. The jobsheet consists of Connect to Wi-Fi, BME 280 sensor, OLED display, and challenge jobsheet. The last section of the module contains the evaluation that will be undertaken by students after completing all experiments.

4) Implementation and evaluation stage: The implementation and evaluation stage was subsequently carried out along with the assessment by teachers with the source of interviews data and user (XI grade of students of Engineering Electronics Industry from A, B, and C class), which consists of a number of samples which have been described previously. The assessment was conducted on the contents of the module by sending the learning module to each student and jobsheet in the form of video for each test which can be viewed by students on YouTube. The limited test also conducted to four students who will conduct the experiments and evaluations about quizzes created to determine students' understanding after doing the experiment, it consisted of seven multiple questions and three open-ended question.

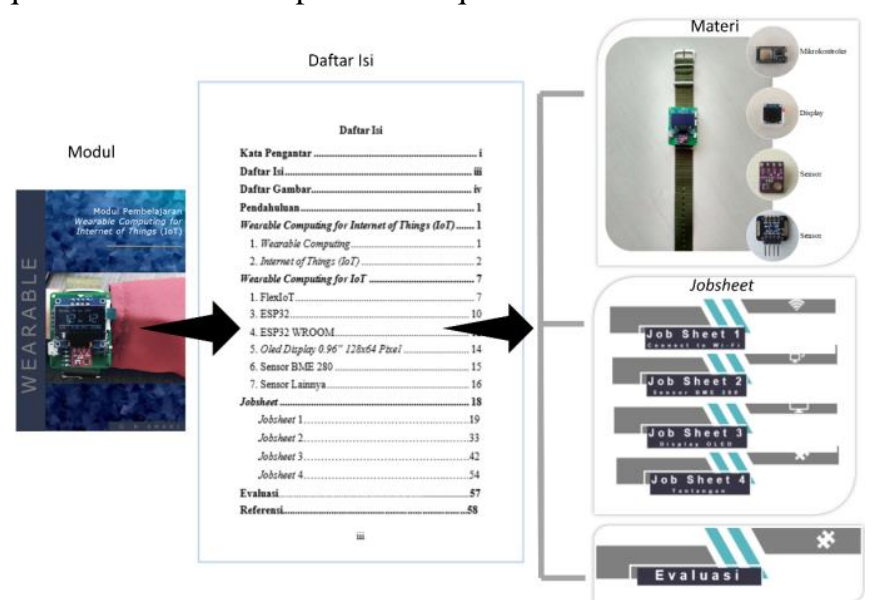

Fig. 3. Results of learning module development.

\section{B. Interview}

For the first question, the answer given indicated that this learning module has the new appearance, uncommon and it is associated with daily life, and it is able to trigger students' interest to learn this learning module, the contents of this learning module are already quite detailed and reliable. This learning module can be juxtaposed with other learning sources and used as the final series of the learning process. But there must be several advance stages that should be carried out and provide an obvious overview of the purpose of this learning module. The material in this learning module has been sufficient and detailed with the purpose of learning. In another word, this module is supported by a learning which has been given gradually for the basis of this learning module. This learning module is very helpful for teachers in delivering material especially those material that related to daily life. Hence, this learning module can be beneficial to develop the learning that is associated with the tools encountered in daily life. This learning module is already suitable with students who have reached the intellectual level of $\mathrm{C} 3$. 


\section{Questionnaire}

1) Demographic data: Demographic data were taken to determine the condition of students who filled out the questionnaire by knowing the number of male and female students, age, computer skills, the usage of Arduino, and comprehension of IoT. As described in the previous chapter, the questionnaire data were taken from 32 samples with the demographics data of 18 male students $(56 \%)$ and 14 female students in total (44\%). The range of students' age is $16-18$ years with a mean age of 17 and a standard deviation of 0.54 . The number of students in class A is 10 students $10(31 \%), 11$ students of B class (34\%) and 11 students of C class (34\%). The detail of demographic data are as follows.

TABLE I. DEMOGRAPHIC DATA

\begin{tabular}{|l|l|l|l|}
\hline Demographic Data & \multicolumn{1}{|c|}{ Information } & Total & Percentage \\
\hline \multirow{3}{*}{ Computer ability } & Less & 3 & $9 \%$ \\
\cline { 2 - 4 } & Fair & 26 & $81 \%$ \\
\cline { 2 - 4 } & Advanced & 3 & $9 \%$ \\
\hline \multirow{3}{*}{ Arduino usage } & Less & 5 & $16 \%$ \\
\cline { 2 - 4 } & Fair & 26 & $81 \%$ \\
\cline { 2 - 4 } & Advanced & 1 & $3 \%$ \\
\hline \multirow{2}{*}{$\begin{array}{l}\text { Inderstanding } \\
\text { IoT the }\end{array}$} & Less & 10 & $31 \%$ \\
\cline { 2 - 4 } & Sufficiently Understand & 20 & $63 \%$ \\
\cline { 2 - 4 } & Understanding & 2 & $6 \%$ \\
\hline
\end{tabular}

Table I displays the demographics data that describe the condition of students who were investigated, the question is filled by students through Google Form with the results of Computers Capabilities: 1$)$ less $(\mathrm{n}=3,9 \%), 2)$ sufficient $(\mathrm{n}=$ 26, $81 \%)$ and 3 ) advanced $(\mathrm{n}=3,9 \%)$. The use of Arduino: 1$)$ less $(\mathrm{n}=5,16 \%), 2)$ sufficient $(\mathrm{n}=26,81 \%)$, and 3$)$ advance $(\mathrm{n}=1,3 \%)$. Comprehension of IoT: 1$)$ low comprehension ( $\mathrm{n}$ $=10,31 \%), 2)$ average comprehension $(n=20,63 \%)$, and high comprehension $(n=2,6 \%)$. The results of the question "whether this module can be used in the class": 1$)$ Yes $(n=30$, $94 \%)$ and 2$)$ No $(n=2,6 \%)$ from all classes of students.

2) Mann-Whitney's U Test: It is obtained the calculation results of Mann-Whitney's U Test using R Studio, as follows: Comparison of Responses Between Male and Female Students

The questionnaire responses of 18 male and 14 female students will be compared with the Mann-Whitney's U Test, and the results can be seen on the Table II below. The statement is said to have a significant difference if the p-value $<0.05$ or the $\mathrm{p}$-value $<0.01[11]$.
TABLE II. THE COMPARISON OF MANN WhITNEY'S U TEST BETWEEN MALE AND FEMALE

\begin{tabular}{|l|c|c|c|c|c|c|}
\hline \multirow{2}{*}{ Assessment Aspects } & \multicolumn{2}{|c|}{ Male } & \multicolumn{2}{c|}{ Female } & \multicolumn{2}{c|}{$\begin{array}{c}\text { Mann-Whitney's U } \\
\text { Test }\end{array}$} \\
\cline { 2 - 7 } & $\boldsymbol{M}$ & $\boldsymbol{S D}$ & $\boldsymbol{M}$ & $\boldsymbol{S D}$ & $\boldsymbol{Z}$ & $\boldsymbol{P}$-Value \\
\hline $\begin{array}{l}\text { Learning Module } \\
\text { Desig }\end{array}$ & 3.4 & 0.3 & 3.2 & 0.23 & 1.4073 & 0.1557 \\
\hline $\begin{array}{l}\text { Use and Learning } \\
\text { Module Materials }\end{array}$ & 3.2 & 0.36 & 3.2 & 0.31 & -0.3069 & 0.7587 \\
\hline $\begin{array}{l}\text { Benefits of Learning } \\
\text { Modules }\end{array}$ & 3.3 & 0.37 & 3.2 & 0.31 & 0.87647 & 0.3897 \\
\hline
\end{tabular}

From the results of the Mann-Whitney's U Test, it is obtained the results for the design aspects of the learning modules $(Z=1.14073$, $p$-value $=0.1557) p>0.05$. It can be signified that none of the presence of significant difference between male and female students. Thus, it can be stated that both male and female students had the same responses regarding the design of learning module. For the usage and material aspects of the learning module $(Z=-0.3069$, p-value $=$ $0.7587)$ there was no significant difference between male and female students, so it can be said that both had the same responses to this aspect. The aspects of the benefits of learning modules $(Z=0.87647, p$-value $=0.3897)$ there was no significant difference between male and female students, therefore it indicated that both had the same responses regarding the learning modules benefit.

3) Kruskall-Wallis: The calculation with Kruskal-Wallis was carried out in several steps, the first was calculating the Kruskal-Wallis chi-squared and p-value and followed by calculating the Post-hoc test if a significant difference was obtained. The results of the calculation of the Kruskal-Wallis use $\mathrm{R}$ studio was obtained as follows, Table III provides the information regarding the comparison of responses among students of $\mathrm{A}, \mathrm{B}$, and $\mathrm{C}$ class.

TABLE III. KRUSKAL-WALLIS TEST RESUlTS

\begin{tabular}{|c|c|c|c|c|c|c|c|c|}
\hline \multicolumn{2}{|c|}{ Grade A } & \multicolumn{2}{|c|}{ Grade B } & \multicolumn{2}{c|}{ Grade C } & \multirow{2}{*}{$\begin{array}{c}\text { Kruskal-Wallis } \\
\text { chi-squared }\end{array}$} & df & p-value \\
\cline { 1 - 5 } $\boldsymbol{M}$ & $\boldsymbol{S} \boldsymbol{D}$ & $\boldsymbol{M}$ & $\boldsymbol{S D}$ & $\boldsymbol{M}$ & $\boldsymbol{S} \boldsymbol{D}$ & & \\
\hline 3.2 & 0.21 & 3.5 & 0.21 & 3.1 & 0.14 & 36.575 & 2 & $1.143 \mathrm{e}-08^{*}$ \\
\hline
\end{tabular}

The calculation results were obtained for class $\mathrm{A}(\mathrm{M}=3.2$, $\mathrm{SD}=0.21)$, class $\mathrm{B}(\mathrm{M}=3.5, \mathrm{SD}=0.21)$, and class $\mathrm{C}(\mathrm{M}=$ $3.1, \mathrm{SD}=0.14)$. The Kruskal-Wallis chi-squared value was 36,575 with a df of 2 and a p-value $<0.01$.

4) Post-hoc test: After recognizing the value of KruskalWallis test ( $\mathrm{p}$-value $<0.01$ ), it can be concluded that there was a significant difference to the responses among students from A, B, and C class. Hence, Post-hoc test with Bonferroni correction was conducted in order to know in detail about the differences of each class what course and the results of it can be seen on Table IV below. 
TABLE IV . RESULT OF POST-HOC TEST

\begin{tabular}{|l|l|l|}
\hline \multicolumn{3}{|c|}{ Bonferroni } \\
\hline \multicolumn{1}{|c|}{ p-value } & \multicolumn{1}{|c|}{ Grade A } & \multicolumn{1}{c|}{ Grade B } \\
\hline Grade B & $0.0007 *$ & - \\
\hline Grade C & 0.0778 & $1.7 \mathrm{e}-08 *$ \\
\hline
\end{tabular}

In Table IV, it was found the significant difference between class A and B with a p-value $<0.01$, class B and C with $p$-value $<0.01$. Further, the calculation was carried out with the Exact Wilcoxon Mann-Whitney Rank Sum Test to get the $\mathrm{Z}$ value, the result is shown in the table $\mathrm{V}$ below.

TABLE V. Z Z AND R VALUES

\begin{tabular}{|c|c|c|}
\hline \multirow{2}{*}{ Grade } & $\mathrm{Z}$ & $\begin{array}{c}\text { Effect Size }(\mathrm{r}) \\
\end{array}$ \\
& & $r=\frac{Z}{\sqrt{N}}$ \\
\hline A and B & 3.6792 & 0.2007168 \\
\hline B and C & 5.8291 & 0.3106921 \\
\hline
\end{tabular}

From the calculation results using Kruskal-Wallis, it can be concluded that the Kruskal Wallis test revealed a significant effect of Class on Value $(x 2(2)=36.575, p<0,01)$. Post-hoc test using Mann-Whitney test with Bonferroni correction showed the significant differences between class A and B ( $p$ $<0.01, r=0.2007168)$, between class $\mathrm{B}$ and $\mathrm{C}(\mathrm{p}<0.01, \mathrm{r}=$ $0.3106921)$. In other words, there is a significant difference of the responses of students among class $\mathrm{A}, \mathrm{B}$, and $\mathrm{C}$ towards the assessment of the module which is divided into several aspects: the design, usage, materials, and benefits.

From the results of the questionnaire distribution, it can be concluded that overall students had been able to use the computer, quite understand about the usage of Arduino because students were majoring at Engineering Electronics Industry program, in which they were required to use the programming language of $\mathrm{C} / \mathrm{C}++$. Meanwhile, there were still a lot of students who did not quite understand about IoT, mostly students only had the average comprehension level of IoT, and other students were had low comprehension of IoT.

Mann-Whitney's U-test was performed to compare the responses between male and female students regarding learning module. The result was obtained and it signified that it was no significant differences of responses between male and female students, it can be said that their responses were almost the same for the assessment of the design, the usage, materials, and the benefits of the learning module. Kruskal-Wallis was used to compare the responses of more than two groups, which were class A, B, and C. From this testing, the result was obtained that indicated there was no significant differences among the classes for the assessment of the design, use, materials, and benefits of learning module. It can be concluded that students from class $\mathrm{A}, \mathrm{B}$, and $\mathrm{C}$ have different responses towards the learning module development of Wearable Computing for IOT. Pairwise comparisons using Wilcoxon rank sum test with Bonferroni method was done to obtain more detailed result about which class that had significant differences and it revealed that both of class $\mathrm{A}$ and $\mathrm{B}$ had the significant difference of their responses regarding the module. Besides, class $\mathrm{B}$ and $\mathrm{C}$ also had significant difference for the response to this learning module.

From the limited test towards the learning module, it was obtained the results that students had been able to follow the procedure properly and get the experiment result which was in accordance with the module objectives. The evaluation results using the quiz which consists of 10 questions that illustrate students' comprehension regarding the work principles that exist in each experiment. Question number one is about the constituent components of wearable computing, question number two is about the work principle of the IoT, question number three is about the data exchange model on MQTT, question number six is about what pin that provided on the BME280 sensor, and question number seven is about drawing the appropriate of publish or subscribe mechanisms. All of four students answered these questions correctly. For question number four and five that related to the publish/subscribe mechanism which subscribe to a topic and SCL SDA pin on ESP32, one out of four students answered these questions was failed to answer these questions correctly. Thus, it can be concluded that through this limited test, students had started to understand the materials that exist on the module.

\section{CONCLUSION}

Based on the research that had been carried out, there are several, learning module development produces a selfcontained module where there are the complete teaching materials included jobsheet and evaluation. This project-based module is created to develop the creativity of students and follow the recent development of the technology. Teachers provide feedback that the module's contents are quite detailed and has been reliable, it is delivered in a new packaging or appearance, and also related to the daily life. This learning module that can increase students' interest. Besides, this module can be developed in the classroom with the provisions of becoming the final purpose of the lesson. This module is able to provide an overview for the students to get involved in the learning process with the attractive material and challenging jobsheet to trigger their creativity.

\section{ACKNOWLEDGMENT}

This journal and the research behind it would not have been possible without the extraordinary support of our advisors. His enthusiasm, knowledge and meticulous attention to detail have inspired and made our work as well as for tvet which has provided us with the opportunity to present the results of the writing of this journal.

\section{REFERENCES}

[1] P. Verma, R. Rajnish, and S. Fatima, "Challenges: Wearable Computing for Internet of Things (IoT)," Int. J. Sci. Res., vol. 6, no. 4, hal. 13061311, 2017. 
[2] X. Xu, "Wearable computer device design for environmental perception system," J. Adv. Oxid. Technol., vol. 21, no. 2, hal. 829-838, 2018, doi: 10.26802/jaots.2018.07013.

[3] M. Liandana, "Penerapan Teknologi LoRa pada Purwarupa Awal Wearable Device,” Res. Comput. Inf. Syst. Technol. Manag., vol. 2, no. 2, hal. 40, 2019, doi: 10.25273/research.v2i02.5191.

[4] A. Shanmugam AL, "A Rudimentary Design Of Wearable Computing Device,” Int. J. Eng. Trends Technol., vol. 41, no. 5, hal. 238-241, 2016, doi: 10.14445/22315381/ijett-v41p244.

[5] M.I. Sani, G.A. Mutiara, and R.S.D.W. Putra, "Fit-NES: Wearable bracelet for heart rate monitoring," Telkomnika (Telecommunication Comput. Electron. Control., vol. 17, no. 1, hal. 392-399, 2019, doi: 10.12928/TELKOMNIKA.v17i1.11611.

[6] C. Syihab and M. Ali, "Pengembangan Modul Pembelajaran Gambar Teknik Autocad Berbasis Project Based Learning Untuk SMK Program
Keahlian Teknik Instalasi Tenaga Listrik," J. Pendidik. Tek. Mekatronika, vol. 8, no. 4, hal. 327-334, 2018.

[7] N. Jalinus, R.A. Nabawi, and A. Mardin, "The Seven Steps of Project Based Learning Model to Enhance Productive Competences of Vocational Students," no. January, 2017, doi: 10.2991/ictvt-17.2017.43.

[8] R.M. Branch, Instructional design: The ADDIE approach. 2010.

[9] I. Etikan, "Comparison of Convenience Sampling and Purposive Sampling," Am. J. Theor. Appl. Stat., vol. 5, no. 1, hal. 1, 2016, doi: 10.11648/j.ajtas.20160501.11.

[10] K. Yatani, Mann-Whitney's U test, 2014. [Online] Retrieved from: https://yatani.jp/teaching/doku.php?id=hcistats:mannwhitney.

[11] D. Wahyudin, S. Hasegawa, and A. Kamaludin, "Students' viewpoint of computer game for training in Indonesian universities and high schools,' Educ. Inf. Technol., vol. 22, no. 4, hal. 1927-1945, 2017, doi: 10.1007/s10639-016-9522-9. 